\title{
Mechanical parameters of cementitious materials with superabsorbent polymer admixture
}

\author{
Jan Fořt ${ }^{1, *}$ Jiři Maděra ${ }^{1}$ and Martin Mildner ${ }^{1}$ \\ ${ }^{1}$ Department of Materials Engineering and Chemistry, Faculty of Civil Engineering, Czech Technical \\ University in Prague, Thákurova 7, Prague 6, 166 29, Czech Republic
}

\begin{abstract}
Concrete despite many performed studies still requires further research on material optimization towards its improvements. On this account the superabsorbent polymers can be viewed as very promising materials with a positive influence on various properties of cementitious materials. The beneficial effect of SAPs on mitigation of autogenous shrinkage or rapid cracks self-healing. However, the absorption capability of SAPs also poses a risk for the formation of dense structure and loss in material durability. The performed study contemplating the influence of two grades of SAP admixtures on mechanical parameters of designed concrete. Obtained results revealed an adverse effect of SAPs on compressive strength. This finding can be assigned to a rapid swelling capability of SAPs, thus a formation of voids in material structure and a significant increase in the total open porosity. Incorporation of about 1.5 wt. $\%$ of SAP admixture decreased compressive strength about almost $50 \%$ compared to the reference sample.
\end{abstract}

\section{Introduction}

Concrete is the most used building material with annual worldwide production of about 10 billion tons. Such an extensive utilization of concrete is promoted by its excellent mechanical properties, long-term durability, and fire resistance. Additionally, concrete structures exhibited excellent resistance to varying climatic conditions or when exposed to chemical deterioration agents. However, despite the indisputable advances, the formation of the crack induced by a periodical loading can be perceived as a major weakness of this material [1]. The overcoming of this issue poses a promising way for the improvement in material durability, prolongation of concrete service life and mitigation of deterioration processes accompanied with the corrosion of steel reinforcement. This problem mainly identified in high-performance concrete (HPC) structures attracted substantial attention of engineers and material designers. Performed investigations revealed an adverse effect of applied low water/binder ratio, undesired $\mathrm{CaO} / \mathrm{SiO}_{2}$ ratio or even incorporation of unsuitable coarse aggregates were found as possible triggers for latter described long-term durability-related problems [2].

*Corresponding author: jan.fort@ffsv.cvut.cz 
Among the other factors, a substantial issue connected with the crack propagation problems arises as a result of increase hydration heat release accompanied with a quick drop of internal relative humidity. These phenomenons ongoing during the curing period often lead to the self-desiccation and high autogenous shrinkage and consequently formed cracks can create entrance paths for undesired water and other harmful substances from the environment which can promote further deterioration [3].

Across the literature, several attempts aimed at the utilization of various techniques for the manual repair of concrete structures suffering from crack formation or material deterioration can be distinguished. However, most of present methods consist only in the external application of the epoxy, polyurethane or concrete coating by electrodeposition of chemical compounds, However, feasibility of such methods is limited thanks to unattractiveness, high price or time-consuming application. Moreover, the cracks formed at the not easily accessible places hinder the repair works and further reduce the effectiveness of repairs. To be specific, within the European Union region, repair and maintenance costs related to this issue represent about half of the total annual construction budget [4].

A new approach based on the utilization of so-called smart materials represents a perspective solution thanks to broad applicability for advanced engineering purposes. Materials, known as superabsorbent polymers (SAP) or hydrogels, are currently mostly used for hygienic applications (diapers, napkins and other biomedical purposes). Nonetheless, the successful implementation of SAPs can also be found in the agricultural sector as nutrient carriers, water reservoirs, and soil conditioners. SAPs characterized by its excellent ability to absorb and hold a significant amount of water can be easily employed for several application fields including the construction sector. The swelling capacity of SAPs is dependent on the solution $\mathrm{pH}$ thus the use in cement-based composites has a crucial effect on the consumption of batch water due to higher ionic concentration $\left(\mathrm{Ca}^{2+}\right.$, $\left.\mathrm{K}^{+}, \mathrm{OH}^{-}\right)$. The correlation between the SAPs absorbability and concentration of dissolved ions in batch water was studied by Roig-Flores et al. [5] in order to evaluate the suitability of various SAPs as a self-healing admixture in cement-based materials.

Work of Hung et al. [6] concluded that utilization of SAPs can provide significant benefits mainly due to rapid healing capability of cracks. Specifically, it was revealed that the application of SAPs in fiber-reinforced concrete substantially promoted self-healing capability of mortars and cracks with a width up to $0.13 \mathrm{~mm}$ was completely sealed. Moreover, Hong and Choi [7] highlighted rapid swelling of SAPs and the ability to seal cracks in material within 5 minutes. Across the literature, several studies concluding an adverse effect of SAPs incorporation on mechanical properties can be distinguished, but on the other hand, recently published review papers revealed a positive influence of SAPs on the cement hydration which results in improvement of strength at later ages $[1,4]$. From this point of view, incorporation of SAPs to concrete mixtures still requires further robust investigation in order to provide a coherent understanding in the field of self-healing.

Based on recent literature, the incorporation SAPs can result in both positive and negative effect on mechanical results, thus the application of SAPs in cementitious composites struggle with many problems despite a great potential in building industry.

The submitted study provides the assessment of the relationship between the amount of applied SAPs and obtained basic physical and mechanical parameters at 3, 7, 14 and 28 days to contribute to the understanding of all related factors responsible for the strength development. 


\section{Materials and methods}

\subsection{Studied materials}

Studied concrete mixtures were composed by following components: Portland cement CEM I $42.5 \mathrm{R}$, silica sand with a maximum particle size of $2 \mathrm{~mm}$, batch water and superabsorbent polymers. Here, two grades of SAPs (Evonic) with different particle size distribution were used. Comparison of particle size distribution curves is given in Fig. 1. The powder density of Cabloc CT SAP is $690 \mathrm{~kg} / \mathrm{m}^{3}$, respectively $600 \mathrm{~kg} / \mathrm{m}^{3}$ Creabloc SIS SAP.

The particle size distribution curves of Portland cement and both SAPs are presented in Figure 1. They were measured on a laser diffraction principle using an Analysette 22 Micro Tec plus device (Fritsch). Performed particle size analysis revealed significantly higher diameter of Cabloc CT with the maximum close to $320 \mu \mathrm{m}$. On the contrary, the maximum of Creasorb SIS was about $36 \mu \mathrm{m}$, i. e. very close to a particle size of Portland cement.

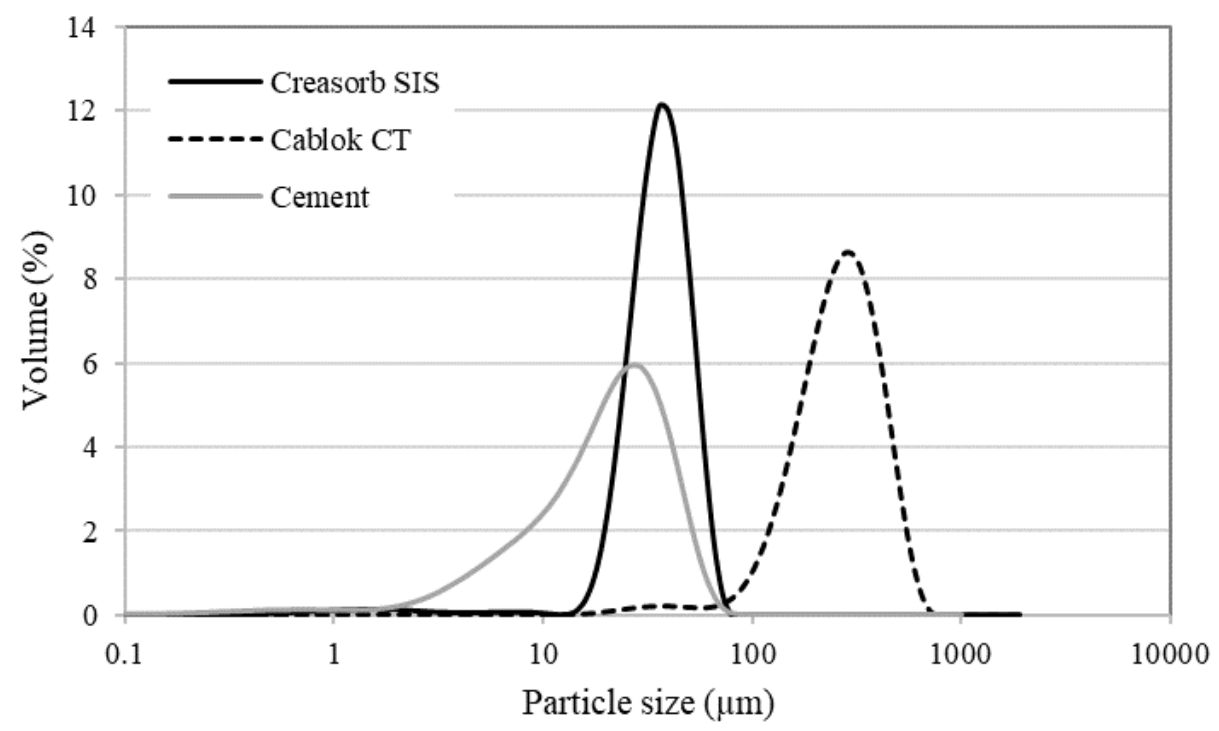

Fig. 1. Particle size distribution curve.

The composition of the designed plasters is shown in Table 1. SAP admixture was used in three different dosages for each material, namely $0.5 ; 1$ and $1.5 \mathrm{wt} . \%$ of cement dosage.

To maintain the same workability of designed mixtures, the amount of batch water was increased to compensate for the excessive water consumption induced by application of SAPs. The workability was within the samples preparation verified using flow table according to standard ČSN EN 12350-5. Reference concrete mixture is denoted as RC, mixtures with $0.5 ; 1 ; 1.5$ wt.\% of SAPs as CabC $0.5,1$ and 1.5 for Cabloc CT SAP, respectively CreC $0.5 ; 1 ; 1.5$ for Creabloc CT SAP. The moulds were filled by using a vibrating table. All samples were cured in the standard conditions at a temperature of $21 \pm 1$ ${ }^{\circ} \mathrm{C}$ and $100 \% \mathrm{RH}$. 
Table 1. Mixture proportions

\begin{tabular}{|l|c|c|c|c|}
\hline Mixture & Cement $\left(\mathbf{k g} / \mathbf{m}^{\mathbf{3}}\right)$ & Sand $\left.\mathbf{( k g} / \mathbf{m}^{\mathbf{3}}\right)$ & SAP $\left.\mathbf{( k g} / \mathbf{m}^{\mathbf{3}}\right)$ & Water $\left.\mathbf{( k g} / \mathbf{m}^{\mathbf{3}}\right)$ \\
\hline RC & 600 & 1250 & - & 340 \\
\hline CabC 0.5 & 578 & 1169 & 3.25 & 365 \\
\hline CabC 1 & 549 & 1074 & 6.5 & 395 \\
\hline CabC 1.5 & 521 & 987 & 9.75 & 435 \\
\hline CreC 0.5 & 581 & 1176 & 3.25 & 360 \\
\hline CreC 1 & 555 & 1094 & 6.5 & 390 \\
\hline CreC 1.5 & 527 & 1007 & 9.75 & 425 \\
\hline
\end{tabular}

\subsection{Experimental methods}

For the developed plasters, measurements of the bulk density, matrix density and total open porosity were done. The bulk density was determined on five cubic samples with a side of $50 \mathrm{~mm}$, by measuring the sample dimensions and its dry mass. The matrix density was measured on helium pycnometry principle using a Pycnomatic ATC apparatus (Thermo Scientific). From the known values of bulk density and matrix density, the total open porosity was calculated [8].

A total of 3 prisms with a size of $160 \mathrm{~mm} \times 40 \mathrm{~mm} \times 40 \mathrm{~mm}$ were tested for each batch. Finally, the compressive strength test was performed at 3, 7, 14 and 28 days. The measurement of the compressive strength was done by the hydraulic testing device VEP WPM Leipzig having a stiff loading frame with the capacity of $3000 \mathrm{kN}$.

\section{Results and discussion}

Looking at the data, a clear effect of SAP incorporation on basic material properties can be found. Obtained results proved that higher SAP dosages, thanks to the increased absorption capability, reduced the bulk density of all studied mixtures as an effect of higher consumption of the batch water. The increased w/c ratio shifted the total open porosity in line with the growing SAP dosages. Namely, the initial total open porosity about $15.41 \%$ was incresed up to almost $24 \%$ for CabC 1.5 mixture. Nevertheless, according to the findings of Tang et al. [9], the explanation of this phenomena can be found in the filling of porous space by swelled SAP particles. Such an effect can be beneficial in later age for a further development of the mechanical strength promoted by continuous hydration. Comparison of applied SAP materials did not reveal any significant changes, notwithstanding the mixtures with incorporated Cablok CT SAP resulted in slightly higher total open porosity, which is related to the lower diameter of particles and thus higher reactivity and swelling capability of compared to Creablok SIS SAP. 
Table 1. Basic physical properties of studied concrete mixtures

\begin{tabular}{|l|c|c|c|}
\hline Mixture & $\begin{array}{c}\text { Bulk density } \\
\left(\mathbf{k g} / \mathbf{m}^{\mathbf{3}}\right)\end{array}$ & $\begin{array}{c}\text { Matrix density } \\
\left(\mathbf{k g} / \mathbf{m}^{\mathbf{3}}\right)\end{array}$ & $\begin{array}{c}\text { Total open } \\
\text { porosity } \mathbf{( \% )}\end{array}$ \\
\hline RC & 2190 & 2589 & 15.41 \\
\hline CabC 0.5 & 2115 & 2576 & 17.89 \\
\hline CabC 1 & 2025 & 2579 & 21.50 \\
\hline CabC 1.5 & 1953 & 2564 & 23.84 \\
\hline CreC 0.5 & 2120 & 2580 & 17.82 \\
\hline CreC 1 & 2046 & 2573 & 20.50 \\
\hline CreC 1.5 & 1969 & 2569 & 23.37 \\
\hline
\end{tabular}

The development in compressive strength at 3, 7, 14 and 28 days is plotted in Fig. 2. The reference mixture reached the highest compressive strength at all ages. On the contrary, the mechanical parameters were gradually decreased in line with increased dosages of applied SAP admixtures. This finding clearly corresponds to the obtained growth in the total open porosity. Increased SAP dosages led to the formation of more voids resulting in decreased compressive strength. While the compressive strength of reference mixture exceeded $46 \mathrm{MPa}$, incorporation of $1.5 \mathrm{wt}$ \% SAP lowered the compressive strength to 28 $\mathrm{MPa}$. The strength of specimens in earlier ages was steadily decreased compared to reference mixture. Notwithstanding, the percentual loss in mechanical parameters is more significant at the earliest age and samples maturing further decreased this drop. On this account, a more substantial increase in later age can be expected.

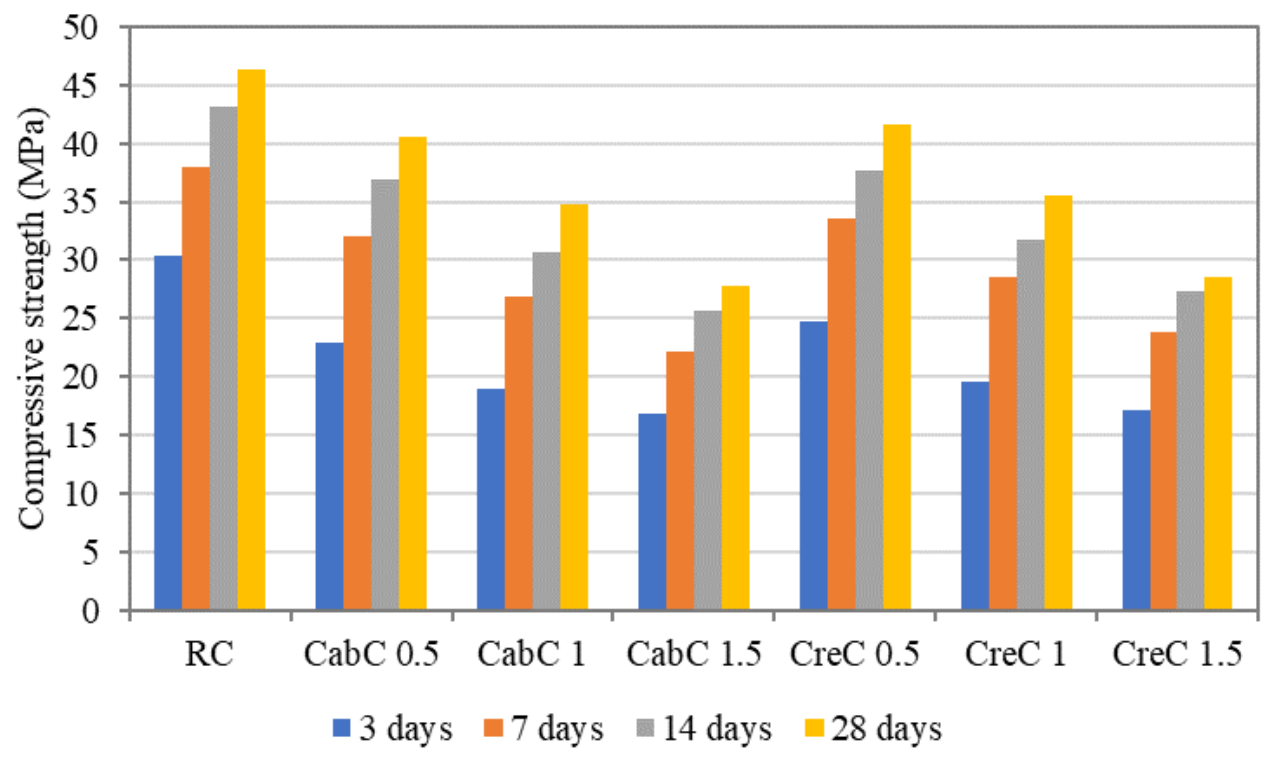

Fig. 2. The compressive strength of studied mixtures

\section{Conclusions}

The effect of superabsorbent polymers on basic physical and mechanical properties of the concrete mixture was investigated in the present paper. Obtained results revealed a 
significant reduction in achieved mechanical properties, which can be assigned to a rapid swelling capability of SAPs, thus a formation of voids in material structure and a substantial increase in the total open porosity. Incorporation of about $1.5 \mathrm{wt} . \%$ of SAP admixture lowered compressive strength about almost 50\% compared to the reference sample. On the other hand, storage moisture in SAP particles can positively affect the development of compressive strength at later ages. Despite the overall positive effect of utilization of SAP admixtures for the minimization of autogenous shrinkage or cracks selfhealing in concrete described in several papers, a loss in mechanical parameters poses the main barrier for broader application in building practice. The further study aimed at the development of mechanical properties at later ages can be beneficial to describe the longterm impact of such material and promote its utilization.

The authors greatly acknowledge the financial support of the Czech Science Foundation under project No. 19-14789S.

\section{References}

1. K. Van Tittelboom, N. De Belie, Materials 6, 2182 (2013)

2. G. Yildirim, O. Keskin, S. Keskin, M. Sahmaran, M. Lachemi, Constr. Build. Mater. 101, 10 (2015)

3. S. Zhutovsky, K. Kovler, Cem. Concr. Res. 42, 20 (2012)

4. H. Liu, Q. Zhang, Ch. Gu, H. Su, V.Li, Cem. Concr. Comp. 82, 14 (2017)

5. M. Roig-Flores, S. Moscato, P. Serna, L. Ferrara, Constr. Build. Mater. 86, 1 (2015)

6. Ch-Ch. Hung, Y-F- Su, Y-M. Su, Compos. Part B-Eng. 133, 15(2018)

7. G. Hong, S. Choi, Constr. Build. Mater. 143, 366 (2017)

8. Z. Pavlík, M. Jerman, J. Fořt, R. Černý, Int. J. Thermophys. 36 (2-3), 557 (2015)

9. W. Tang, O. Kardani, H. Cui, Constr. Build. Mater. 81, 233 (2015) 